\title{
Analyses of Wind Energy Impact on WFEC System Operations
}

\section{Technical Report} NREL/TP-500-37851

August 2005

\section{Y. Wan}

National Renewable Energy Laboratory

J.R. Liao

Western Farmers Electric Cooperative

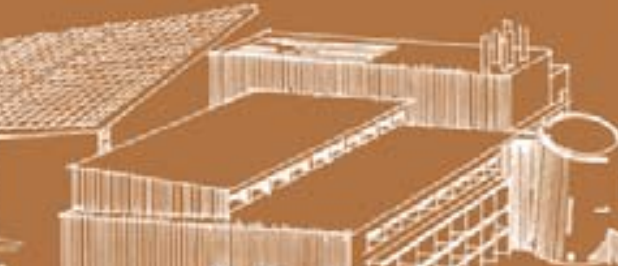




\section{Analyses of Wind Energy Impact on WFEC System Operations}

Y. Wan

National Renewable Energy Laboratory

J.R. Liao

Western Farmers Electric Cooperative

Prepared under Task No(s). WER5.5101

National Renewable Energy Laboratory

1617 Cole Boulevard, Golden, Colorado 80401-3393

303-275-3000 • www.nrel.gov

Operated for the U.S. Department of Energy

Office of Energy Efficiency and Renewable Energy

by Midwest Research Institute $\bullet$ Battelle

Contract No. DE-AC36-99-G010337

Technical Report NREL/TP-500-37851

\section{August 2005}

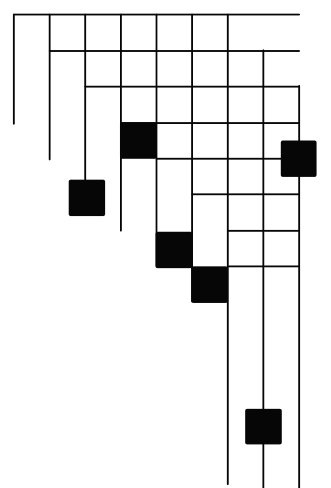




\section{NOTICE}

This report was prepared as an account of work sponsored by an agency of the United States government. Neither the United States government nor any agency thereof, nor any of their employees, makes any warranty, express or implied, or assumes any legal liability or responsibility for the accuracy, completeness, or usefulness of any information, apparatus, product, or process disclosed, or represents that its use would not infringe privately owned rights. Reference herein to any specific commercial product, process, or service by trade name, trademark, manufacturer, or otherwise does not necessarily constitute or imply its endorsement, recommendation, or favoring by the United States government or any agency thereof. The views and opinions of authors expressed herein do not necessarily state or reflect those of the United States government or any agency thereof.

Available electronically at http://www.osti.gov/bridge

Available for a processing fee to U.S. Department of Energy and its contractors, in paper, from:

U.S. Department of Energy

Office of Scientific and Technical Information

P.O. Box 62

Oak Ridge, TN 37831-0062

phone: 865.576 .8401

fax: 865.576 .5728

email: mailto:reports@adonis.osti.gov

Available for sale to the public, in paper, from:

U.S. Department of Commerce

National Technical Information Service

5285 Port Royal Road

Springfield, VA 22161

phone: 800.553.6847

fax: 703.605.6900

email: orders@ntis.fedworld.gov

online ordering: http://www.ntis.gov/ordering.htm 


\section{Contents}

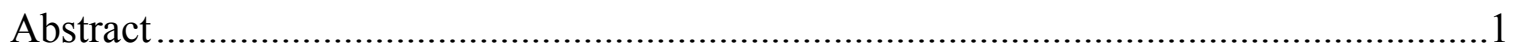

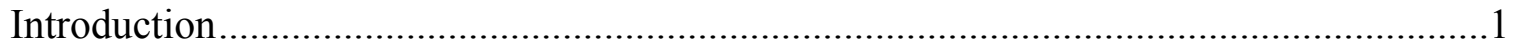

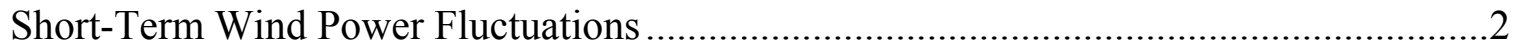

Short-Term Load Variations ...................................................................................

Variability of System Load with Wind Power..........................................................6

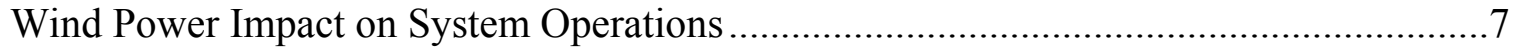

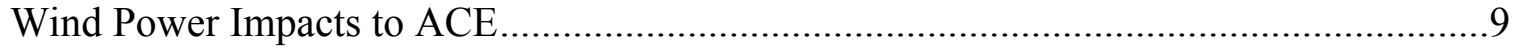

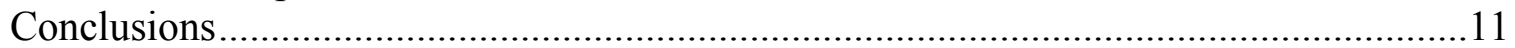

\section{Tables}

Table 1. Statistics of 10-minute Wind Power Step Changes ...........................................

Table 2. Statistics of Hourly Wind Power Step Changes ...............................................4

Table 3. Standard Deviations of 1-Minute Wind, Load, and Apparent Load

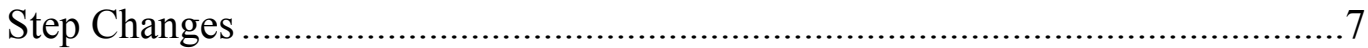

Table 4. Hourly Variability with Wind Power............................................................... 7

Table 5. Example Daily Correlation Coefficients from 1-Minute Data Series...................8

\section{Figures}

Figure 1. Frequency distribution of 10 -minute wind power step changes.........................

Figure 2. Distribution of hourly wind power step changes............................................4

Figure 3. Profiles of 1-minute average wind power and system load ................................5

Figure 4. Wind power and system load fluctuations details .........................................5

Figure 5. Correlation between ACE and interchanges.............................................10

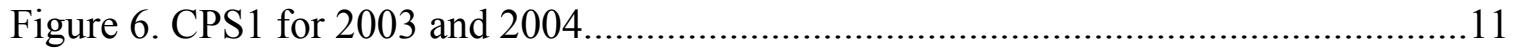

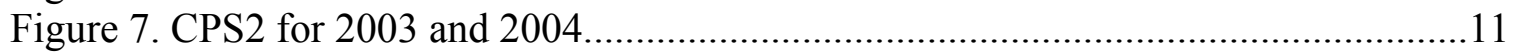




\section{Abstract}

Western Farmers Electric Cooperative (WFEC) is a generation and transmission Cooperative in Oklahoma. At the end of 2003 it added 74 megawatts (MW) of wind energy to its energy portfolio by purchasing the output of the Blue Canyon Wind Power Project located north of Lawton, Oklahoma. The wind energy has the potential to provide about $6 \%$ of WFEC's peak summer energy demand. During periods of high winds and low loads, wind energy may represent $14 \%$ of the control area load. Conversely during periods of calm wind, wind energy cannot be counted upon to provide any energy to WFEC's system. This report analyzes system and wind energy data recorded by the WFEC control area energy management system (EMS) and evaluates the effects of wind energy on system operations.

The results show that, at low penetration levels, wind energy has a very small effect on system operations. After the addition of wind power, WFEC continues to meet the control performance standard 1 and 2 (CPS1 and CPS2) requirements for area control error (ACE) with some adjustments in operating procedures and reserve margin. There were no significant changes in the ACE that can be attributed to wind energy. The fluctuation of wind energy caused only a slight increase in the variability of the overall system load. The data showed that on average the standard deviation of the 1-minute system apparent load (system load minus wind power) is about $10 \%$ higher than that of the system load alone. System regulation needs are still dominated by short-term, random load changes. For hourly system apparent load, the increase is even smaller (about 4\%).

\section{Introduction}

The Western Farmers Electric Cooperative (WFEC) is a generation and transmission cooperative in Oklahoma. It operates one coal-fired and four gas-fired power plants (two steam plants, one combined-cycle plant, and one gas turbine plant). With 279 megawatts (MW) of federal allocated hydro power, WFEC has a combined capacity of 1,400 MW. In 2003, the WFEC added $74 \mathrm{MW}$ (nameplate rating) of wind power to its energy portfolio when it entered into an energy only purchase agreement with the Blue Canyon Wind Power Project located north of Lawton, Oklahoma. The project consists of 45 NEG Micon 1.65 MW turbines. The $74 \mathrm{MW}$ of wind power represents about $6 \%$ of the WFEC system peak demand.

To analyze the effects of wind energy on its system operations, WFEC collected 1-minute data from the EMS system. Below is a sample of the 1-minute EMS data stream which includes (1) time stamp, (2) wind power, (3) 1-minute sliding average area control error (ACE), (4) frequency, (5) system load, (6) actual interchange, (7) scheduled interchange, and (8) total on-line generation (wind power and other generation combined). A negative interchange value means power was imported into the control area. The example below shows the system was scheduled to import $239 \mathrm{MW}$ (column 7) at 19:46 central standard time (CST), and the actual import was $243.16 \mathrm{MW}$. 


$\begin{array}{cccccccc}\begin{array}{c}(1) \\ \vdots\end{array} & (2) & (3) & (4) & (5) & (6) & (7) & (8) \\ 19: 46: 00 & 53.23 & 2.82 & 60.01 & 796.71 & -243.16 & -239 & 553.56 \\ 19: 47: 00 & 53.14 & 1.99 & 60.01 & 795.54 & -244.14 & -239 & 551.39 \\ 19: 48: 00 & 52.57 & -2.95 & 60.01 & 797.34 & -248.00 & -239 & 549.33 \\ 19: 49: 00 & 54.56 & 1.82 & 60.01 & 794.91 & -243.29 & -239 & 551.63 \\ 19: 50: 00 & 55.73 & 5.22 & 60.01 & 792.83 & -240.18 & -239 & 552.65 \\ 19: 51: 00 & 54.82 & 2.96 & 60.02 & 793.22 & -243.32 & -239 & 549.90 \\ 19: 52: 00 & 56.21 & 1.16 & 60.01 & 793.55 & -244.91 & -239 & 548.64 \\ 19: 53: 00 & 56.95 & 0.88 & 60.02 & 793.73 & -245.92 & -239 & 547.81 \\ 19: 54: 00 & 55.64 & 2.19 & 60.03 & 793.09 & -245.80 & -239 & 547.28 \\ 19: 55: 00 & 57.86 & 1.73 & 60.01 & 791.19 & -244.48 & -239 & 546.71\end{array}$

In addition to 1-minute data stream from the EMS, 10-minute average wind power data series are also available. The 10-minute data series are from wind plant supervisory control and data acquisition (SCADA) system.

\section{Short-Term Wind Power Fluctuations}

Short-term wind power fluctuations are stochastic in nature. Wind power can be higher, lower or remain the same from one instant to the next. To gauge the variability of Blue Canyon wind power, statistics and distribution of output single step changes (the step changes are differences between two consecutive values of wind power in a time series) are calculated from the 10minute wind power data series and hourly average power data series (derived from the 10-minute data series). Step changes indicate wind power persistence.

Table 1 compares the monthly standard deviation values of 10 -minute wind power series from the Blue Canyon Project, two Midwest wind power plants (Lake Benton in Minnesota and Storm Lake in Iowa), and four Texas wind power plants (Indian Mesa, King Mountain, Trent Mesa, and Texas Wind Power Project [TWPP]). The average values of the monthly step changes (positive and negative) are nearly zero for all cases, and therefore, are not shown. Numbers in the lower portion of the table are the normalized standard deviation values obtained by dividing the standard deviation values with the nameplate rating of respective wind power plants. During 10minute intervals, the standard deviation of power level changes at Blue Canyon range from 3.7 $\mathrm{MW}$ to $5.0 \mathrm{MW}$, or within the range of $5 \%$ to $7 \%$ of nameplate rating. It can be seen that the 10-minute fluctuations of Blue Canyon wind power plant are similar to that of the other wind power plants. When more data are included in computing, the standard deviation values of step changes of all large wind power plants expressed in terms of nameplate rating are remarkably close. 
Table 1. Statistics of 10-minute Wind Power Step Changes

\begin{tabular}{|c|c|c|c|c|c|c|c|}
\hline & Blue Canyon & Lake Benton & Storm Lake & Indian Mesa & King Mtn & Trent Mesa & $T W P P$ \\
\hline & Stdev (MW) & Stdev (MW) & Stdev (MW) & Stdev (MW) & Stdev (MW) & Stdev (MW) & Stdev (MW) \\
\hline January & 3.7 & 4.0 & 3.5 & 2.4 & 2.3 & 5.3 & 1.3 \\
\hline February & 3.1 & 3.7 & 3.1 & 2.7 & 2.6 & 5.4 & 1.2 \\
\hline March & 4.1 & 4.2 & 4.6 & 3.0 & 2.4 & 5.9 & 1.3 \\
\hline April & 4.1 & 3.6 & 3.9 & 4.0 & 3.8 & 6.6 & 1.4 \\
\hline May & 3.8 & 5.0 & 5.2 & 3.1 & 3.5 & 5.7 & 1.6 \\
\hline June & 5.0 & 3.8 & 3.4 & 3.9 & 3.4 & 7.8 & 1.6 \\
\hline July & 4.4 & 3.3 & 3.1 & 2.6 & 1.9 & 5.7 & 1.3 \\
\hline August & 3.8 & 3.8 & 3.3 & 2.6 & 1.8 & 5.1 & 1.0 \\
\hline September & 3.9 & 4.5 & 3.6 & 2.3 & 2.6 & 4.3 & 0.8 \\
\hline 9 months & 4.0 & 4.0 & 3.9 & 3.0 & 2.8 & 5.9 & 1.3 \\
\hline \multicolumn{8}{|c|}{ Normalized Standard Deviation } \\
\hline January & $5 \%$ & $4 \%$ & $3 \%$ & $3 \%$ & $3 \%$ & $4 \%$ & $4 \%$ \\
\hline February & $4 \%$ & $4 \%$ & $3 \%$ & $3 \%$ & $3 \%$ & $4 \%$ & $3 \%$ \\
\hline March & $6 \%$ & $4 \%$ & $4 \%$ & $4 \%$ & $3 \%$ & $4 \%$ & $4 \%$ \\
\hline April & $6 \%$ & $4 \%$ & $3 \%$ & $5 \%$ & $5 \%$ & $4 \%$ & $4 \%$ \\
\hline May & $5 \%$ & $5 \%$ & $5 \%$ & $4 \%$ & $5 \%$ & $4 \%$ & $5 \%$ \\
\hline June & $7 \%$ & $4 \%$ & $3 \%$ & $5 \%$ & $4 \%$ & $5 \%$ & $5 \%$ \\
\hline July & $6 \%$ & $3 \%$ & $3 \%$ & $3 \%$ & $2 \%$ & $4 \%$ & $4 \%$ \\
\hline August & $5 \%$ & $4 \%$ & $3 \%$ & $3 \%$ & $2 \%$ & $3 \%$ & $3 \%$ \\
\hline September & $5 \%$ & $4 \%$ & $3 \%$ & $3 \%$ & $3 \%$ & $3 \%$ & $2 \%$ \\
\hline 9 months & $5 \%$ & $4 \%$ & $3 \%$ & $4 \%$ & $4 \%$ & $4 \%$ & $4 \%$ \\
\hline
\end{tabular}

Figure 1 shows the distribution of Blue Canyon wind power 10-minuste step changes. Eightyfour percent of all step changes are within $\pm 1 \sigma$ ( $\pm 4 \mathrm{MW}$ or $\pm 5 \%$ of nameplate rating). Ninetynine percent of all 10 -minute step changes are within $\pm 3 \sigma( \pm 12 \mathrm{MW}$ or $\pm 16 \%$ of nameplate rating).

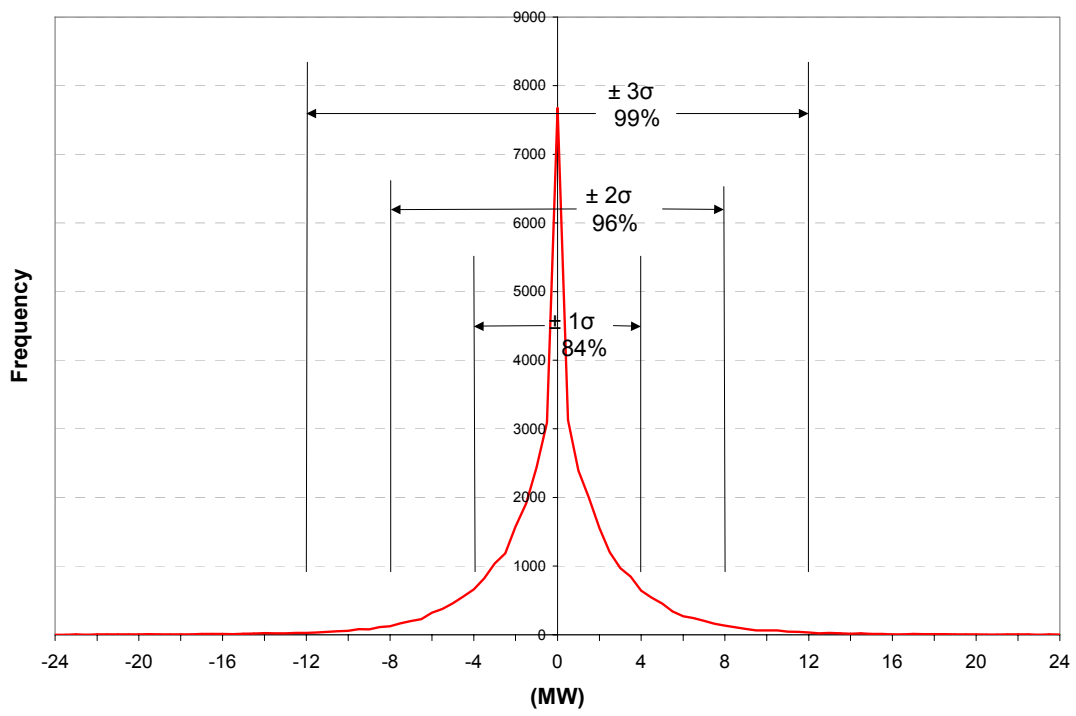

Figure 1. Frequency distribution of 10-minute wind power step changes

Table 2 shows the hourly wind power changes. Again numbers in the lower half of the table are the standard deviation values in terms of plant rating. Wind power level variation may be larger during longer time frames. The standard deviation of hourly wind power changes at Blue Canyon ranges from $6.2 \mathrm{MW}$ to $8.6 \mathrm{MW}$ ( $8 \%$ to $12 \%$ of the nameplate rating). Again there is little difference in the hourly statistics between Blue Canyon and other large wind power plants. 
Table 2. Statistics of Hourly Wind Power Step Changes

\begin{tabular}{|c|c|c|c|c|c|c|c|}
\hline & Blue Canyon & Lake Benton & Storm Lake & Indian Mesa & King Mtn & Trent Mesa & $T W P P$ \\
\hline & Stdev (MW) & Stdev (MW) & Stdev (MW) & Stdev (MW) & Stdev (MW) & Stdev (MW) & Stdev (MW) \\
\hline January & 7.6 & 9.6 & 10.0 & 6.0 & 5.3 & 14.6 & 3.7 \\
\hline February & 7.2 & 9.3 & 9.0 & 6.7 & 5.5 & 14.3 & 3.1 \\
\hline March & 8.5 & 9.7 & 12.3 & 7.2 & 5.6 & 15.3 & 3.7 \\
\hline April & 7.6 & 8.8 & 11.5 & 9.0 & 8.1 & 16.9 & 3.5 \\
\hline May & 6.9 & 10.9 & 11.8 & 6.9 & 7.5 & 16.8 & 3.4 \\
\hline June & 8.6 & 9.2 & 9.5 & 9.1 & 7.2 & 18.7 & 4.1 \\
\hline July & 7.7 & 7.9 & 6.7 & 5.7 & 3.6 & 16.2 & 2.7 \\
\hline August & 6.2 & 9.5 & 9.1 & 5.5 & 3.5 & 12.6 & 2.4 \\
\hline September & 6.4 & 9.9 & 8.7 & 6.5 & 5.4 & 12.2 & 2.0 \\
\hline 9 months & 7.4 & 9.5 & 10.1 & 7.0 & 6.0 & 15.5 & 3.3 \\
\hline \multicolumn{8}{|c|}{ Normalized Standard Deviation } \\
\hline January & $10 \%$ & $9 \%$ & $9 \%$ & $7 \%$ & $7 \%$ & $10 \%$ & $11 \%$ \\
\hline February & $10 \%$ & $9 \%$ & $8 \%$ & $8 \%$ & $7 \%$ & $10 \%$ & $9 \%$ \\
\hline March & $11 \%$ & $9 \%$ & $11 \%$ & $9 \%$ & $7 \%$ & $10 \%$ & $11 \%$ \\
\hline April & $10 \%$ & $9 \%$ & $10 \%$ & $11 \%$ & $10 \%$ & $11 \%$ & $10 \%$ \\
\hline May & $9 \%$ & $11 \%$ & $10 \%$ & $8 \%$ & $9 \%$ & $11 \%$ & $10 \%$ \\
\hline June & $12 \%$ & $9 \%$ & $8 \%$ & $11 \%$ & $9 \%$ & $13 \%$ & $12 \%$ \\
\hline July & $10 \%$ & $8 \%$ & $6 \%$ & $7 \%$ & $5 \%$ & $10 \%$ & $8 \%$ \\
\hline August & $8 \%$ & $9 \%$ & $8 \%$ & $7 \%$ & $4 \%$ & $8 \%$ & $7 \%$ \\
\hline September & $9 \%$ & $10 \%$ & $8 \%$ & $8 \%$ & $7 \%$ & $8 \%$ & $6 \%$ \\
\hline 9 months & $10 \%$ & $9 \%$ & $9 \%$ & $9 \%$ & $8 \%$ & $10 \%$ & $9 \%$ \\
\hline
\end{tabular}

Figure 2 shows the hourly wind power step changes at Blue Canyon are scattered over a wider range. However $98 \%$ of all hourly step changes are still within $\pm 3 \sigma( \pm 22.5 \mathrm{MW}$ or $\pm 30 \%$ of nameplate rating).

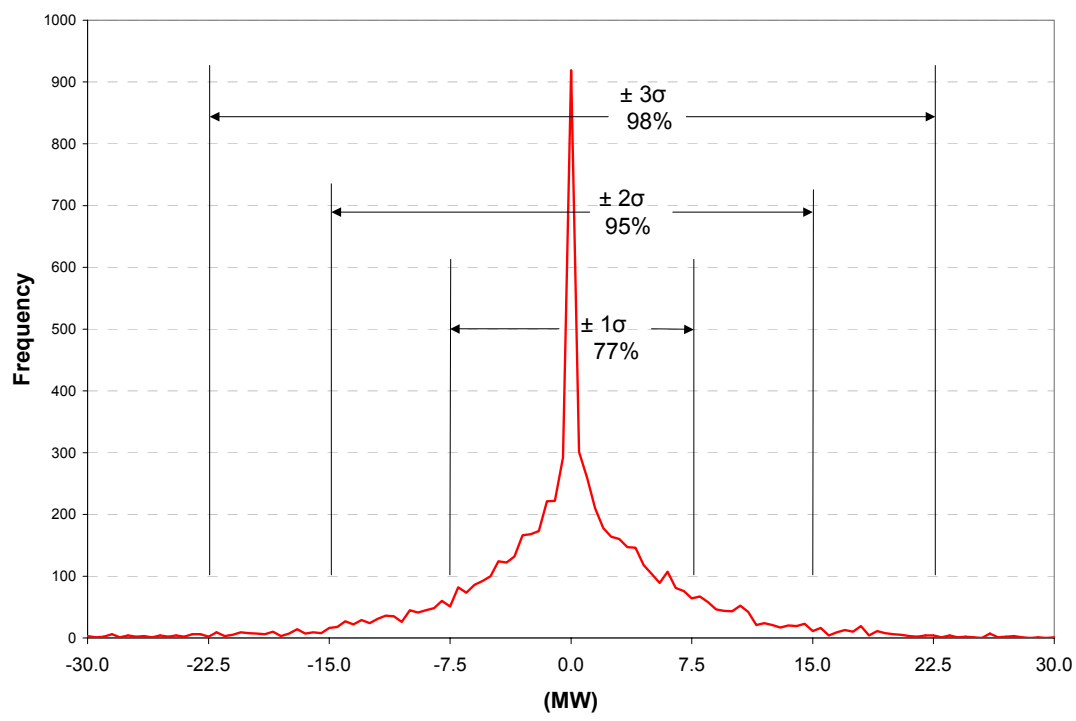

Figure 2. Distribution of hourly wind power step changes 


\section{Short-Term Load Variations}

A utility system load has a well-defined, predictable daily pattern that corresponds to daylight and routine human activities. Figure 3 plots the 1-minute average load (green trace) and wind power (blue trace) during a 17-hour period. The general trend of the system load-morning load pick-up, late evening peak and nightly load drop-off — is clear. A utility can usually forecast these trends fairly accurately based on experience, weather forecast, and knowledge about load within its service territory. The plot shows that the system load also contains a rapid-changing component (the zigzag in the load profile trace) that is similar to the short-term wind power fluctuations. These short-term fluctuations are stochastic in nature.

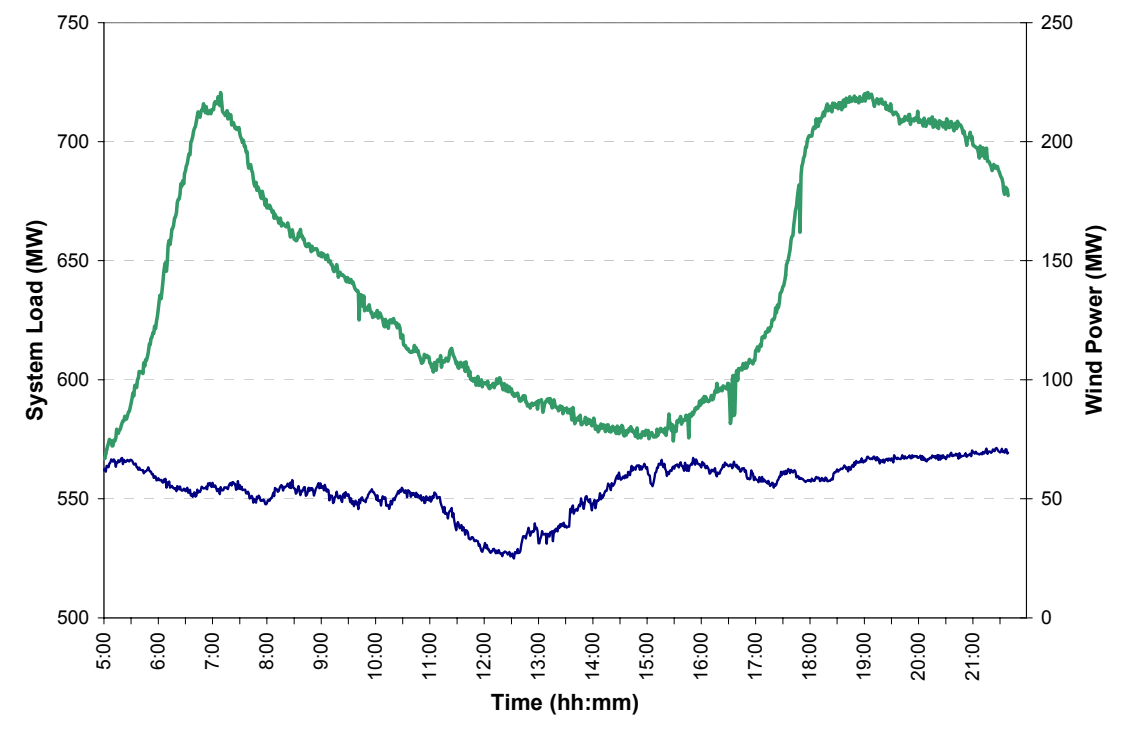

Figure 3. Profiles of 1-minute average wind power and system load

To show the rapid fluctuations of load and wind power in detail, Figure 4 plots the 1-minute average load and wind power for a three-hour period. It is obvious that the system load and wind power short-term changes are very similar.

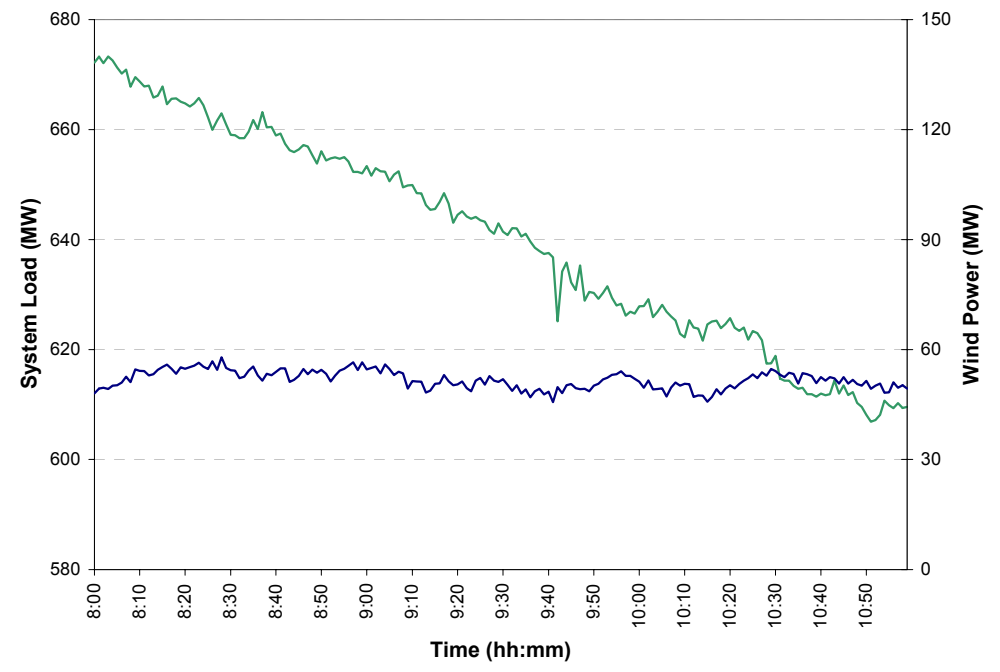

Figure 4. Wind power and system load fluctuations details 
During the 17-hour period, wind power step changes are within the range of $7.5 \mathrm{MW}$ and -5.4 MW with an average value of $0.0 \mathrm{MW}$ and a standard deviation value of $1.3 \mathrm{MW}$. The system load exhibits a higher volatility than the wind power. During the same period the system load step changes vary between 24.0 MW and-20.0 MW. The system load step changes have an average value of $0.1 \mathrm{MW}$ and a standard deviation value of $2.4 \mathrm{MW}$.

While the data show there is positive but weak correlation between the short-term fluctuations of system load and wind power, they are two independent events. The daily correlation coefficients between 1-minute step changes of load and wind power ranges from 0.03 to 0.22 . This suggests that wind power tends to move in the same direction as the system load. From a system operations point of view, this is a desirable situation. However, this specific phenomena could be associated with the limited available data. There is no reason for the short-term fluctuations of wind power and system load to be related. More short-term data should provide a clearer picture.

\section{Variability of System Load with Wind Power}

The electric system responds to the short-term load fluctuations by adjusting the outputs of some of its online generating units which can change its output quickly and are under automatic generation control (AGC). This function, called regulation, helps a control area maintain its interchange schedule, support its system frequency, and balance its generation and load under normal operations.

When wind power is added to a utility system control area, the system must respond to fluctuations of both system load and wind power. One way to gauge the effect of wind power on system regulation requirement is to examine the variability of wind power, system load and the apparent load (i.e., load minus wind power) ${ }^{1}$. The fluctuations of the apparent load are the combination of load and wind power fluctuations, and they represent the regulation requirements to the system after wind power is added. Table 3 lists the standard deviation values of wind power $\left(\sigma_{\mathrm{W}}\right)$, system load $\left(\sigma_{\mathrm{L}}\right)$ and apparent load step changes $\left(\sigma_{\mathrm{A}}\right)$ and their extreme values from a 1 -minute data series. ${ }^{2}$

Table 3 shows that the apparent load has a higher variability than the system load. The apparent load is smaller in magnitude than the system load, but its step changes generally have larger standard deviation values. Although this indicates that wind power causes the variability of the apparent load to increase, which in turn increases the system regulation requirement, the increases are relatively moderate. Compared to the step changes of the system load alone, the step changes of the apparent load have a standard deviation value that ranges from no change to $26 \%$ larger. The average increase is about $10 \%$. The small changes in both maximum positive and negative step change values also suggest that little additional regulation is required by wind power. As shown in the table, the addition of wind power only slightly increases the extreme values of apparent load step changes.

\footnotetext{
${ }^{1}$ Here wind power is treated as a negative load because WFEC does not regulate the Blue Canyon output. Whenever wind power is available, the rest of the control area generating units will see a reduced load.

2 The average values are not listed because they all are very small or zero, and reveal no information.
} 
Table 3. Standard Deviations of 1-Minute Wind, Load, and Apparent Load Step Changes

\begin{tabular}{|c|c|c|c|c|c|c|c|c|c|}
\hline \multicolumn{4}{|c|}{ Standard Deviation (MW) } & \multicolumn{3}{|c|}{ Maximum (+) Step Change (MW) } & \multicolumn{3}{|c|}{ Maximum (-) Step Change (MW) } \\
\hline $\begin{array}{c}\text { Wind Step } \\
\sigma_{\mathrm{W}}\end{array}$ & $\begin{array}{c}\text { Load Step } \\
\sigma_{\mathrm{L}}\end{array}$ & $\begin{array}{c}\text { Apparent } \\
\text { Load Step } \\
\sigma_{\mathrm{A}}\end{array}$ & $\%$ change & Wind Step & Load Step & $\begin{array}{l}\text { Apparent } \\
\text { Load Step }\end{array}$ & Wind Step & Load Step & $\begin{array}{l}\text { Apparent } \\
\text { Load Step }\end{array}$ \\
\hline 0.8 & 1.7 & 1.7 & - & 4.7 & 14.0 & 14.0 & $(4.5) \dagger$ & $(9.9)$ & $(9.9)$ \\
\hline 1.3 & 1.6 & 1.9 & $19 \%$ & 4.9 & 7.2 & 6.1 & $(4.3)$ & $(6.0)$ & $(6.4)$ \\
\hline 1.3 & 2.7 & 2.8 & $4 \%$ & 4.2 & 44.3 & 42.9 & (5.6) & (40.4) & $(40.2)$ \\
\hline 1.0 & 1.4 & 1.6 & $14 \%$ & 4.2 & 8.7 & 7.5 & (5.4) & (4.3) & $(5.8)$ \\
\hline 0.8 & 1.6 & 1.7 & $6 \%$ & 3.4 & 4.4 & 4.9 & $(3.8)$ & $(13.0)$ & $(13.0)$ \\
\hline 0.5 & 1.3 & 1.3 & - & 3.2 & 5.0 & 4.7 & (3.4) & $(5.2)$ & (4.9) \\
\hline 0.6 & 1.3 & 1.4 & $8 \%$ & 3.0 & 5.5 & 5.5 & (3.5) & (4.5) & (4.6) \\
\hline 1.1 & 1.6 & 1.8 & $13 \%$ & 3.7 & 5.7 & 5.8 & $(4.0)$ & (5.2) & $(7.0)$ \\
\hline 1.4 & 1.7 & 2.1 & $24 \%$ & 3.4 & 5.0 & 5.1 & (5.6) & $(15.8)$ & (16.8) \\
\hline 0.8 & 1.4 & 1.5 & $7 \%$ & 3.8 & 6.1 & 6.0 & (4.0) & $(6.0)$ & $(7.0)$ \\
\hline 1.1 & 2.9 & 3.0 & $3 \%$ & 4.7 & 49.9 & 49.3 & (4.5) & $(50.3)$ & $(50.4)$ \\
\hline 1.0 & 1.9 & 2.1 & $11 \%$ & 7.2 & 23.5 & 23.5 & (7.3) & (25.1) & (25.1) \\
\hline 1.8 & 2.9 & 3.3 & $14 \%$ & 6.3 & 36.1 & 37.3 & $(7.0)$ & (37.1) & (38.8) \\
\hline 1.0 & 1.5 & 1.7 & $13 \%$ & 4.5 & 5.4 & 6.5 & (4.6) & $(6.2)$ & $(8.2)$ \\
\hline 1.3 & 2.4 & 2.7 & $13 \%$ & 7.5 & 24.0 & 24.5 & (5.4) & $(20.0)$ & $(20.5)$ \\
\hline 1.7 & 1.9 & 2.4 & $26 \%$ & 7.1 & 12.6 & 14.0 & (5.5) & (13.5) & (14.0) \\
\hline 1.2 & 1.7 & 2.0 & $18 \%$ & 3.1 & 6.1 & 7.8 & (3.9) & $(6.7)$ & (6.9) \\
\hline 1.1 & 5.3 & 5.4 & $2 \%$ & 5.5 & 90.7 & 91.5 & (5.2) & $(94.0)$ & $(92.3)$ \\
\hline 0.8 & 17.2 & 17.2 & - & 3.4 & 382.8 & 383.1 & (3.6) & $(383.8)$ & (383.2) \\
\hline 0.4 & 1.5 & 1.5 & - & 3.3 & 6.9 & 7.6 & (3.4) & (5.3) & (4.8) \\
\hline
\end{tabular}

tparentheses denote negative numbers

Table 4 shows the hourly step change statistics for wind power, system load, and apparent load. It shows that the addition of wind power causes only a slight increase in the hourly variability of the apparent load (4\%). The differences in apparent load step change extreme values are also relatively small (about $11 \%$ ).

Table 4. Hourly Variability with Wind Power

\begin{tabular}{lcccc}
\hline & $\begin{array}{c}\text { Wind Step Changes } \\
\text { (MW) }\end{array}$ & $\begin{array}{c}\text { Load Step Changes } \\
\text { (MW) }\end{array}$ & $\begin{array}{c}\text { Apparent Load Step Changes } \\
\text { (MW) }\end{array}$ & \% Change \\
\hline Standard Deviation & 7.3 & 30.3 & 31.6 & $4 \%$ \\
Max (+) Step & 31.6 & 90.5 & 99.5 & $10 \%$ \\
Max (-) Step & $(20.7)$ & $(81.2)$ & $(90.1)$ & $11 \%$ \\
\hline
\end{tabular}

\section{Wind Power Impact on System Operations}

To see how system operations are affected by the fluctuations of wind power, the correlation between the wind power step changes and various other system parameters are computed and examined. Table 5 lists the daily correlation coefficients calculated from 1-minute data series.

Column (1) shows the correlation coefficients between wind power step changes and actual interchange step changes. Column (2) shows the correlation coefficients between wind power step changes and control area net online generation (i.e., total generation minus wind power). Column (3) shows the correlation coefficients between system load step changes and actual interchange step changes. Column (4) shows the correlation coefficients between system load 
step changes and net on line generation. Column (5) shows the correlation coefficients between changes in apparent load and actual interchange. ${ }^{3}$ Column (6) shows the correlation coefficients between changes in apparent load and net online generation, and (7) shows the correlation coefficients between wind power step changes and ACE. ${ }^{4}$ Column (8) shows the correlation coefficients between system load step changes and ACE, and column (9) the differences between scheduled and actual interchanges and the ACE.

It should be noted that the numbers in Table 5 are numerical results of mechanic computations performed on random series (such as wind power step changes and system load step changes) of limited length. The absolute values of these numbers are therefore less important than their relative relations and the underlining pattern they display.

\begin{tabular}{|c|c|c|c|c|c|c|c|c|}
\hline (1) & (2) & (3) & (4) & (5) & (6) & (7) & (8) & $\begin{array}{c}\text { (9) } \\
\text { Actual \& }\end{array}$ \\
\hline $\begin{array}{l}\text { Wind } \\
\text { Power }\end{array}$ & $\begin{array}{l}\text { Wind } \\
\text { Power }\end{array}$ & $\begin{array}{c}\text { Load } \\
\text { Changes }\end{array}$ & $\begin{array}{l}\text { Load } \\
\text { Changes }\end{array}$ & $\begin{array}{l}\text { Apparent } \\
\text { Load }\end{array}$ & $\begin{array}{l}\text { Apparent } \\
\text { Load }\end{array}$ & $\begin{array}{l}\text { Wind } \\
\text { Power }\end{array}$ & $\begin{array}{c}\text { Load } \\
\text { Changes }\end{array}$ & $\begin{array}{l}\text { Schedule } \\
\text { Interchange }\end{array}$ \\
\hline Changes & Changes & & & Changes & Changes & Changes & & Differences \\
\hline
\end{tabular}

\begin{tabular}{ccccccccc}
$\begin{array}{c}\text { Actual } \\
\text { Interchange } \\
\text { Changes }\end{array}$ & $\begin{array}{c}\text { Net } \\
\text { Gen } \\
\text { Changes }\end{array}$ & $\begin{array}{c}\text { Actual } \\
\text { Interchange } \\
\text { Changes }\end{array}$ & $\begin{array}{c}\text { Net } \\
\text { Gen } \\
\text { Changes }\end{array}$ & $\begin{array}{c}\text { Actual } \\
\text { Interchange } \\
\text { Changes }\end{array}$ & $\begin{array}{c}\text { Net } \\
\text { Gen } \\
\text { Changes }\end{array}$ & ACE & ACE & ACE \\
\hline$(0.13)$ & $(0.02)$ & 0.40 & 0.23 & 0.45 & 0.23 & 0.04 & $(0.20)$ & 0.93 \\
$(0.33)$ & 0.01 & 0.40 & 0.05 & 0.59 & 0.03 & 0.14 & $(0.05)$ & 0.95 \\
$(0.19)$ & $(0.11)$ & 0.70 & 0.05 & 0.75 & 0.10 & 0.14 & $(0.27)$ & 0.88 \\
$(0.26)$ & $(0.00)^{*}$ & 0.33 & 0.11 & 0.46 & 0.10 & 0.13 & $(0.10)$ & 0.80 \\
$(0.17)$ & $(0.00)^{*}$ & 0.31 & 0.10 & 0.37 & 0.10 & 0.05 & $(0.18)$ & 0.99 \\
$(0.05)$ & $(0.05)$ & 0.45 & 0.14 & 0.48 & 0.16 & 0.04 & $(0.19)$ & 0.83 \\
$(0.12)$ & $(0.10)$ & 0.54 & 0.04 & 0.57 & 0.09 & 0.03 & $(0.13)$ & 0.98 \\
$(0.34)$ & $(0.04)$ & 0.55 & $(0.01)$ & 0.68 & 0.02 & 0.09 & $(0.09)$ & 0.95 \\
$(0.37)$ & $(0.08)$ & 0.50 & 0.10 & 0.68 & 0.15 & 0.11 & $(0.04)$ & 0.95 \\
$(0.19)$ & $(0.08)$ & 0.51 & 0.05 & 0.57 & 0.09 & 0.14 & $(0.06)$ & 0.92 \\
$(0.21)$ & $(0.10)$ & 0.79 & 0.01 & 0.83 & 0.05 & 0.07 & $(0.08)$ & 0.96 \\
$(0.19)$ & $(0.19)$ & 0.64 & 0.09 & 0.67 & 0.17 & 0.13 & $(0.07)$ & 0.97 \\
$(0.41)$ & $(0.03)$ & 0.69 & 0.09 & 0.84 & 0.09 & 0.14 & $(0.15)$ & 0.97 \\
$(0.20)$ & $(0.13)$ & 0.44 & 0.10 & 0.50 & 0.16 & 0.10 & $(0.12)$ & 0.95 \\
$(0.35)$ & $(0.04)$ & 0.66 & 0.14 & 0.77 & 0.15 & 0.07 & $(0.15)$ & 0.97 \\
$(0.47)$ & $(0.03)$ & 0.50 & 0.13 & 0.73 & 0.13 & 0.16 & $(0.19)$ & 0.90 \\
$(0.39)$ & $(0.02)$ & 0.44 & 0.20 & 0.59 & 0.18 & 0.12 & $(0.22)$ & 0.97 \\
$(0.15)$ & $(0.05)$ & 0.90 & 0.05 & 0.92 & 0.07 & 0.03 & $(0.20)$ & 0.99 \\
$(0.01)$ & $(0.06)$ & $1.00 *$ & 0.01 & $1.00 *$ & 0.02 & 0.05 & $(0.69)$ & 0.80 \\
$(0.00) *$ & $(0.03)$ & 0.52 & 0.19 & 0.53 & 0.21 & $(0.02)$ & $(0.28)$ & 0.89 \\
$(0.16)$ & $(0.05)$ & 0.87 & 0.09 & 0.90 & 0.05 & 0.09 & $(0.24)$ & 0.94 \\
\hline Due $)$ & & & & & & & &
\end{tabular}

As shown, there is a negative correlation between wind power step changes and actual interchange step changes. The daily correlation coefficients range from 0.00 to -0.47 and the

\footnotetext{
${ }^{3}$ Here the concept of negative load for wind power is used. Because the system operators do not schedule wind power and all output from Blue Canyon is accepted, the presence of wind power will result in a reduction of apparent system load that is seen by other generators. The apparent load thus is the differences between system load and wind power.

${ }^{4}$ Actual 1-minute average ACE values, not the differences between two consecutive ACE values, were used in computing the correlation coefficients in Table 5, because ACE itself is derived from the differences between actual and scheduled interchanges.
} 
overall correlation coefficient for the entire period is -0.16 (column 1 ). The correlation between wind power changes and net online generation is also negative. The overall correlation coefficient is -0.05 (column 2). The smaller correlation coefficients are associated with low wind power days, and the larger correlation coefficients with high wind power days. The wind power and actual interchange move in opposite directions. When wind power increases, the actual interchange tends to decrease (i.e., less power into the control area).as does the outputs from other online generators. This is an expected outcome. When more power becomes available within the control area (i.e., an increase in wind power), both online generation and power flow into the control area will decrease to maintain the balance between load and generation. The correlation between wind power changes and net online generation is weaker than the correlation between wind power changes and actual interchange. It suggests that the frequency response of the entire grid is faster than that of a single control area. In this case it appears that wind power fluctuations are mostly taken up by the grid in the form of higher interchange variability.

Step changes in actual interchange have a positive and strong correlation with changes of system load. The correlation coefficients range from 0.31 to 1.00 (rounded up from 0.995 ). The overall correlation coefficient is 0.87 (column 3 ). The correlation between changes in load and changes in net online generation is also positive, but weaker; its correlation coefficients range from 0.005 to 0.23 with an overall correlation coefficients of 0.09 (column 4). These results show that when load increases, both online generation and the amount of power imported increase to meet the additional demand. The relative strength of the correlation coefficients between load changes and changes in actual interchange and the correlation coefficients between load changes and changes in net online generation suggests that interchange follows the change of system load more closely. Online generation within the control area also responds to the changes of system load fluctuations, but to a lesser degree than does the interchange. This is similar to responses of the online generation and actual interchange to the changes in wind power discussed in item (1) above. The grid is more responsive to changes of control area load.

It is clear that load fluctuations cause more changes in the interchange than do the wind power fluctuations. Load fluctuations also have more influence on control area net online generation than do the wind power fluctuations. Therefore, the changes in apparent load and actual interchange are highly correlated (column 5). The correlation coefficients between changes in apparent load and actual interchange range from 0.45 to 1.00 (rounded up fro, 0.996) with an overall value of 0.90 . Compared to the strong correlation between changes in apparent load and actual interchange, the correlation between changes in apparent load and control area net online generation is almost nonexistent (column 6).

\section{Wind Power Impacts to ACE}

The efficiency of the system regulation function is measured by ACE statistics. The available data show that wind power fluctuations have minimal influence on ACE for the WFEC control area. The correlation between system load changes and ACE (overall correlation coefficient of 0.24; column 8) is stronger than the correlation between wind power changes and ACE (overall correlation coefficients of 0.09 ; column 7 ). This result reinforces the idea that load fluctuations have a greater impact on system operations than do wind power fluctuations. The positive 
correlation coefficients between wind power step changes and ACE mean both quantities move in the same direction, i.e., increases in wind power tend to associate with positive ACE values and decreases in wind power tend to associate with negative ACE values. The negative correlation coefficients between system load changes and ACE are just the opposite-increases in system load tend to associate with negative ACE values and vise versa. ${ }^{5}$

ACE is derived from the differences between actual and scheduled interchanges, and therefore, a strong correlation between these two is expected. Correlation coefficients calculated from the WFEC 1-minute data series confirms this relationship. The correlation coefficients between ACE and differences of actual and scheduled interchanges range from 0.80 to 0.99 with an overall value of 0.90 (Column 9 in Table 5). Further examination of the data revealed that the majority of the large ACE values (positive and negative) have no relation to either system load changes or wind power changes. Large ACE values occurred during periods when there were large inter-hour interchange schedule changes. The available data have not shown that small short-term wind power fluctuations have any noticeable effect on ACE. Figures 5 is an example of such event. It plots 1-minute actual and scheduled interchanges and their differences,

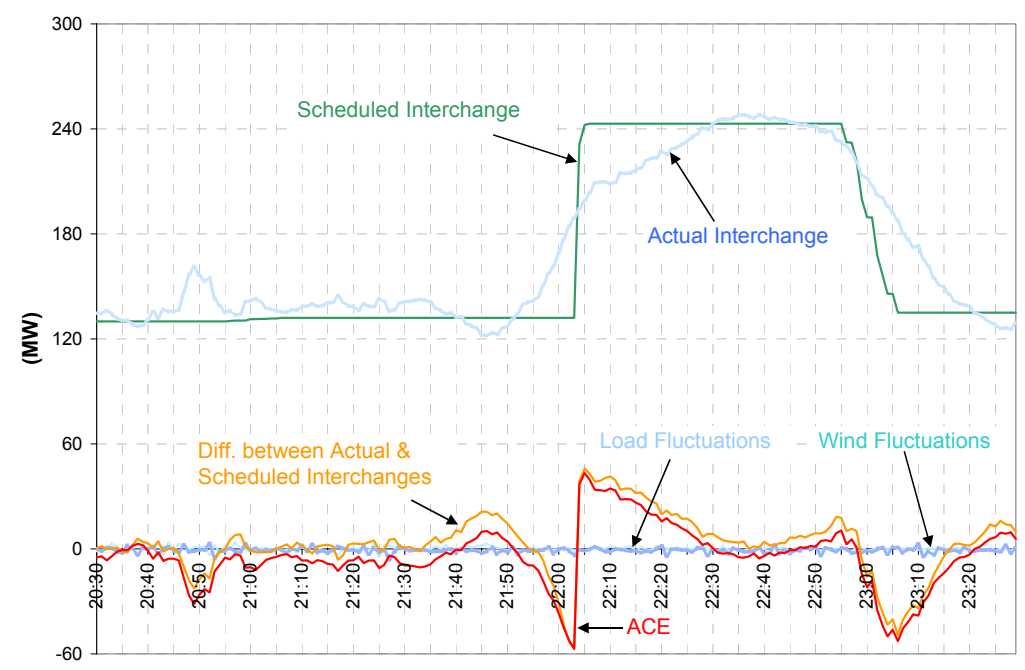

Figure 5. Correlation between ACE and interchanges

1-minute ACE values, and 1-minute step change values of wind power and system load. The figure clearly shows that the ACE has no correlation with either load or wind fluctuations. The ACE tracks the differences between actual interchange and scheduled interchange and becomes very large during periods when the interchange schedule takes a large step change and the generators within the control area have not had time to bring the actual interchange to the new designated level.

All the control areas are required to meet the Control Performance Standard CPS1 and CPS2 requirements. CPS1 measures the long-term impact of ACE on the health of the interconnection

\footnotetext{
${ }^{5}$ According to industry convention, positive ACE indicates power going out and the negative ACE indicates power flowing into the control area.
} 
in terms of frequency. CPS2 measures the short-term excursions (10 minute average) of ACE against a predefined limit for each control area. ${ }^{6}$

The CPS1 and CPS2 graphs for 2003 and 2004 for the WFEC control area are shown in Figures 6 and 7. Although the graphs show that a downward trend of CPS1 before the Blue Canyon wind power plant came on-line in December 2003, it is evident that the CPS1 deterioration accelerated in early 2004 after wind power was included into the control area. Uncertainty of wind power availability affected the unit commitment decisions made by the system operators and worsened CPS1. With more experiences, WFEC system operators began to take corrective actions $^{7}$ in March of 2004 and the CPS1 eventually returned to the level before wind power was added. There is very little difference on CPS2 before and after wind power.

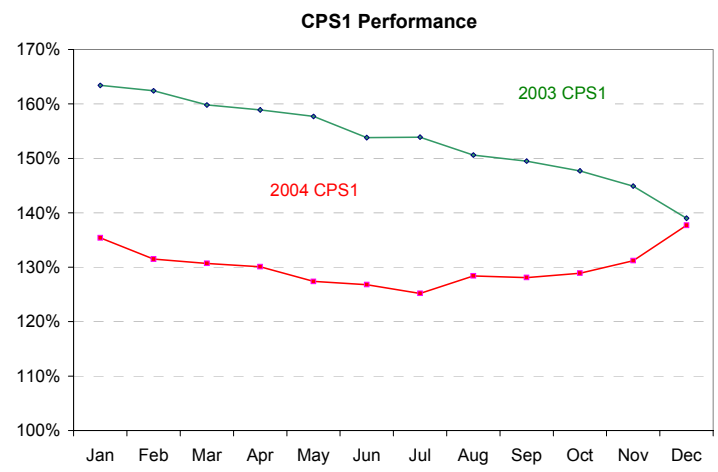

Figure 6. CPS1 for 2003 and 2004

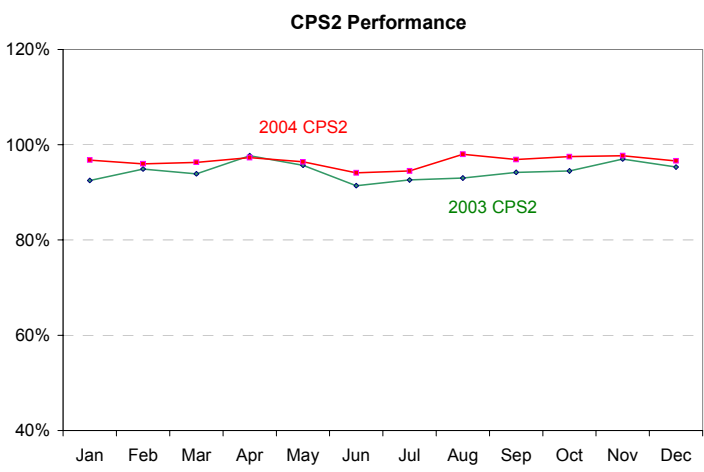

Figure 7. CPS2 for 2003 and 2004

Short-term wind power fluctuations can be accommodated by additional spinning reserve and regulation margin. The uncertainty of wind power availability complicates the day-ahead resources scheduling and hour-ahead adjustment processes, which determine the available spinning reserve and regulation margin. Better wind power forecasting can help improve the system performance. WFEC is working with Blue Canyon Wind Plant operators to improve wind power forecasting. Researchers are currently conducting additional research to determine the sufficient but economic amount of spinning reserve and regulation needed to compensate for wind power fluctuations that considers the uncertainty of wind power forecasting. ${ }^{8}$

\section{Conclusions}

The available data show that wind generation has less impact on system regulation requirements than system load. At low penetration, the impact of wind power on system operations is small. Analyses indicate that the magnitudes of short-term changes in system load are greater than that of wind power, and consequently changes in system load dominate the control area operations.

\footnotetext{
${ }^{6}$ The minimum performance standard is $100 \%$ for CPS1 and 90\% for CPS2.

${ }^{7}$ Including paying closer attention to ACE movement and developing new empirical formula for generator control.

${ }^{8}$ For example: K. Methaprayoon, et. al., "An Integration of ANN Wind Power Estimation into UC Considering the Forecasting Uncertainty,” http://www.ewh.ieee.org/soc/ias/icps2005/
} 
Changes in wind power only had small influence on actual interchange and online generation. Furthermore the correlation between the ACE and changes of system load is much stronger than the correlation between the ACE and wind power changes. The available data show that almost all high ACE values are caused by big changes in interchange schedule.

The generating rating of Blue Canyon Wind Power Project is about 6\% of WFEC's peak load, and about $14 \%$ during light load periods. At such levels, the data show that on average the fluctuations of wind power only increase the short-time frame variability of system apparent load by $10 \%$. For longer-time frame the increase in system apparent load variability is even less.

WFEC CPS1 and CPS2 statistics before and after of wind power was added to the control area confirm that the wind power impacts on system operations are small and manageable. Although compliance with CPS1 showed an initial deterioration (but still within minimum performance standard), it recovered to its pre-wind level after operators gained more experience and made some adjustment in operation procedures. There was very little change in CPS2 compliance.

It is clear that at low penetration level wind variations have much less impact on system regulation requirements than that of load variations. System operators may still consider wind generation harder to manage because it is easier for operators to predict system load than wind power. The operators are more experienced with load forecasting than wind power forecasting and they feel comfortable using load forecasting information in system operations. However, as demonstrated by WFEC CPS1 statistics, operators learn to manage the variability of wind and can maintain satisfactory system performance. Good wind power forecasting is obviously of high value to system operators. Equally import are specific operating procedures on how to use wind power forecasting in control area operations. 


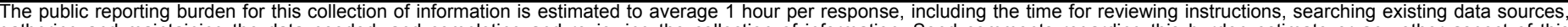

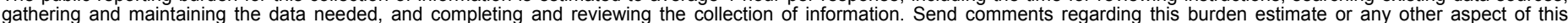

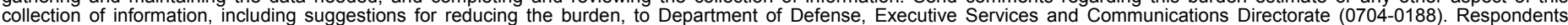

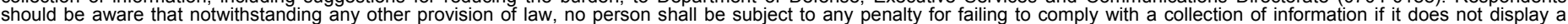

should be aware that notwithstanding

PLEASE DO NOT RETURN YOUR FORM TO THE ABOVE ORGANIZATION.

\begin{tabular}{l|l|l} 
1. $\begin{array}{l}\text { REPORT DATE }(D D-M M-Y Y Y Y) \\
\text { August } 2005\end{array}$ & 2. $\begin{array}{l}\text { REPORT TYPE } \\
\text { Technical Report }\end{array}$ & $\begin{array}{l}\text { 3. } \\
\text { DATES COVERED (From - To) } \\
2003-2005\end{array}$ \\
\hline
\end{tabular}

4. TITLE AND SUBTITLE

Analyses of Wind Energy Impact on WFEC System Operations

5a. CONTRACT NUMBER

DE-AC36-99-G010337

5b. GRANT NUMBER

5c. PROGRAM ELEMENT NUMBER

6. AUTHOR(S)

Y. Wan and J.R. Liao

5d. PROJECT NUMBER

NREL/TP-500-37851

5e. TASK NUMBER

WER5.5101

5f. WORK UNIT NUMBER
7. PERFORMING ORGANIZATION NAME(S) AND ADDRESS(ES)

National Renewable Energy Laboratory

1617 Cole Blvd.

Golden, CO 80401-3393

9. SPONSORING/MONITORING AGENCY NAME(S) AND ADDRESS(ES)
8. PERFORMING ORGANIZATION REPORT NUMBER

NREL/TP-500-37851
10. SPONSOR/MONITOR'S ACRONYM(S)

NREL

11. SPONSORING/MONITORING AGENCY REPORT NUMBER

12. DISTRIBUTION AVAILABILITY STATEMENT

National Technical Information Service

U.S. Department of Commerce

5285 Port Royal Road

Springfield, VA 22161

13. SUPPLEMENTARY NOTES

14. ABSTRACT (Maximum 200 Words)

Western Farmers Electric Cooperative (WFEC) is a generation and transmission Cooperative in Oklahoma. At the end of 2003 it added 74 megawatts (MW) of wind energy to its energy portfolio by purchasing the output of the Blue Canyon Wind Power Project located north of Lawton, Oklahoma. The wind energy has the potential to provide about $6 \%$ of WFEC's peak summer energy demand. During periods of high winds and low loads, wind energy may represent $14 \%$ of the control area load. Conversely during periods of calm wind, wind energy cannot be counted upon to provide any energy to WFEC's system. This report analyzes system and wind energy data recorded by the WFEC control area energy management system (EMS) and evaluates the effects of wind energy on system operations.

15. SUBJECT TERMS

wind energy generation; transmission; Western Farmers Electric Cooperative

16. SECURITY CLASSIFICATION OF:
\begin{tabular}{l|l|l|}
$\begin{array}{c}\text { a. REPORT } \\
\text { Unclassified }\end{array}$ & $\begin{array}{c}\text { b. ABSTRACT } \\
\text { Unclassified }\end{array}$ & $\begin{array}{c}\text { c. THIS PAGE } \\
\text { Unclassified }\end{array}$ \\
\end{tabular}

\begin{tabular}{l|l|}
$\begin{array}{l}\text { 17. LIMITATION } \\
\text { OF ABSTRACT }\end{array}$ & $\begin{array}{l}\text { 18. } \\
\text { NUMBER } \\
\text { OF PAGES }\end{array}$ \\
UL & \\
& \\
\end{tabular}

19a. NAME OF RESPONSIBLE PERSON

19b. TELEPHONE NUMBER (Include area code) 